\title{
O DIREITO DA CRIANÇA COM DEFICIÊNCIA: PROFISSIONAL DE APOIO EM SALA DE AULA
}

\author{
RAFAEL LOPES DE SOUSA* \\ ANDRÉIA MENDES DE OLIVEIRA** \\ VIVIANE VIEIRA HATAKEYAMA***
}

\begin{abstract}
RESUMO
A temática de educação inclusiva à pessoa com deficiência é caracterizada no direito de todos no processo escolar do ensino aprendizagem, por esta razão, apresenta-se: $\mathrm{O}$ direito da criança com deficiência: profissional de apoio em sala de aula. Indaga-se: toda criança com deficiência tem este direito de fato? A criança e o jovem com deficiência têm ganhado espaço dentro das escolas, um fator social que amplamente tem introduzido a necessidade de novas práticas pedagógicas para a inclusão de todas elas. Em maior ou menor escala, o Profissional de Apoio é um agente colaborador nesta trajetória, na busca constante de metodologias e autonomias que, somadas a políticas públicas, possam não só garantir, mas também questionar os aspectos inclusivos necessários.
\end{abstract}

Palavras-chave: Políticas Públicas.Autonomia.Equidade.Práticas Pedagógicas.

* Mestre em História social (UNESP- Assis), Doutor em História Social (UNICAMP). Docente do Programa em Ciências Humanas, nível Mestrado (UNISA).

** Licenciatura em Pedagogia e História, Mestra em Ciências Humanas; professora de educação infantil e ensino fundamental I na rede municipal de ensino da cidade de São Paulo; am7905@gmail.com

*** Mestre em Ciências Humanas, Bacharel em Administração pela Universidade Estácio Radial e Licenciada em Pedagogia; Professora e Tutora dos Cursos de Graduação e Pós Graduação da Educação a Distância; vivianevieira.sousa@yahoo.com.br 


\section{INTRODUÇÃO}

A educação inclusiva para pessoa com deficiência é o processo que garante a matricula de todos os alunos, independentemente de sua condição física ou psíquica na rede regular de ensino. É o resultado de grandes lutas e políticas públicas para esta modalidade de ensino, promovendo mudanças estruturais na educação.

O movimento de Inclusão escolar às crianças com deficiência vem ganhando destaque a cada ano, o aumento de estudantes deficientes nas escolas públicas e privadas, emerge a demanda de ampliação das redes de apoio, nesse contexto um novo parceiro (Profissional de Apoio à Inclusão Escolar) e desta forma a temática: $\mathrm{O}$ direito da criança com deficiência: Profissional de Apoio em sala de aula.

Garantir os direitos conquistados aos estudantes com deficiência é parte de nossas Leis vigentes, Plano Nacional de Educação, Base Nacional Comum Curricular, além de outros Projetos Nacionais, Estaduais e Municipais, assim surge a questão: Toda criança tem este direito de fato? Sabemos que ainda há muito o que se fazer para uma educação inclusiva de direito e de equidade.

O objetivo geral deste artigo é problematizar a garantia do Profissional de Apoio no acompanhamento individualizado à criança com deficiência nos espaços escolares, delineando-se os objetivos específicos: Trajetória histórica e constitucional dos direitos à criança com deficiência e as peculiaridades de deficiências bem como os serviços de apoio.

Historicamente a educação à pessoa com deficiência tem enfrentado grandes lutas no processo afirmativo de valorização para a construção das especificidades da comunidade escolar e construção de um espaço de direitos e deveres, com voz aos envolvidos nas decisões e projetos destinados ao alcance de uma autonomia de diretos mútuos, culminando na demanda aos educandos estudantes com deficiência, no que diz respeito ao Profissional de Apoio, ainda que garantido por lei. 
Assim, realiza-se uma metodologia de caráter com abordagem qualitativa, procedimento bibliográfico e documental básico. Em continuidade aos projetos e políticas públicas que se destinam na constante dinâmica de um processo educacional autoral e coletivo, há que se pensar e se criar conceitos humanizados que culminem em uma educação inclusiva de garantia profissional juntamente a uma rede de apoio, unindo-se em esforços e profissionalismo, na busca de garantir equidade social, cultural e educacional aos docentes com alunos de algum nível de deficiência nas escolas.

Busca-se abordar este tema de forma eloquente, sempre pensando que a criança e o jovem com deficiência, precisam de fato estarem incluídos no processo ensino aprendizagem. Muitas pesquisas ainda precisam ter voz e acesso aos espaços de trabalho aonde houver uma criança com deficiência, trazendo consigo mais uma possibilidade de garantir o direito que lhe é conferido desde sua concepção.

\section{TRAJETÓRIA HISTÓRICA E CONSTITUCIONAL DOS DIREITOS Â CRIANÇA COM DEFICIÊNCIA E SUAS FAMÍLIAS}

Em uma ordem cronológica, podemos destacar historicamente os direitos constitucionais às crianças com deficiência. Entre estes direitos, destaca-se um de grande importância no processo educativo, que é o direito a um profissional de apoio que acompanhe a criança com deficiência em sala de aula.

O Art. 208 da Constituição Federal de 1988 em seu Inciso III destaca o dever do Estado com a educação, mediante a garantia de atendimento educacional especializado às crianças com deficiência, preferencialmente na rede regular de ensino.

Em consonância ao Estatuto da Criança e do Adolescente de 1990, encontramos o Art. 54, Inciso III, o mandamento constitucional que explicita a obrigatoriedade do Estado em garantir e assegurar à criança com deficiência o atendimento 
educacional especializado, preferencialmente na rede regular de ensino. A Lei 9.394/96, Lei de Diretrizes e Bases da Educação Nacional, vem de forma respeitosa e obrigatória, novamente assegurar e orientar o atendimento educacional especializado aos educandos com deficiência.

O Estatuto da Pessoa com Deficiência (Lei 13.146/2015), em vigor no ano de 2016, garante direitos relacionados à acessibilidade, educação, saúde e estabelece ações para atitudes discriminatórias.

Currículos, métodos, técnicas, recursos educativos e organização, específicos para atender às suas necessidades; terminalidade específica para aqueles que não puderem atingir o nível exigido para a conclusão do ensino fundamental, em virtude de suas deficiências [...], professores com especialização adequada em nível médio ou superior, para atendimento especializado, bem como professores do ensino regular capacitados para a integração desses educandos nas classes comuns; educação especial para o trabalho, visando a sua efetiva integração na vida em sociedade, inclusive condições adequadas para os que não revelarem capacidade de inserção no trabalho competitivo, mediante articulação com os órgãos oficiais afins [...] acesso igualitário aos benefícios dos programas sociais suplementares disponíveis para o respectivo nível do ensino regular (BRASIL, 1996, p. 19-20).

Embora esta temática esteja totalmente assistida e garantida constitucionalmente no Brasil, ainda existem muitas dificuldades na promoção e garantia de fato nas escolas. Em muitos casos, as crianças com deficiência possuem autonomia para transitarem e desenvolverem trabalhos educacionais sem necessariamente a presença de um acompanhante, este fator é muito positivo, pois esta criança deve encontrar nos espaços escolares possibi- 
lidades de desenvolver-se como todas as demais, interagindo e compartilhando aprendizagens. Dado este fator, muitas crianças deficientes não são acompanhadas diretamente por um profissional de apoio em sala de aula, podendo se caracterizar como falta de atendimento especializado diante da grande demanda. Há que se avaliar a real necessidade e especificidade de cada uma anteriormente, pois esta avaliação será norteadora na decisão de se ter ou não um acompanhante diretamente ligado a este aluno. "Em casos de comprovada necessidade, a pessoa com transtorno do espectro autista incluída nas classes comuns de ensino regular [...] terá direito a acompanhante especializado". (BRASIL, 2001, p. 2). O decreto 8.368/2014 que regulamenta essa lei afirma que:

Caso seja comprovada a necessidade de apoio às atividades de comunicação, interação social, locomoção, alimentação e cuidados pessoais, a instituição de ensino em que a pessoa com transtorno do espectro autista ou com outra deficiência estiver matriculada disponibilizará acompanhante especializado no contexto escolar, nos termos do parágrafo único do art. 3o da Lei no 12.764, de 2012. (BRASIL, 2001, p. 2).

A elaboração do currículo, na perspectiva de uma escola inclusiva, deve ter sua origem no projeto político pedagógico da escola, promovendo as orientações necessárias para o atendimento destas crianças com deficiências, e desta forma, cabe ressaltar a garantia de uma proposta curricular inclusiva, que fortalecida por metodologias democráticas, promovam a parceria de professores, alunos, escola, famílias e projetos especiais na consolidação das práticas e políticas públicas para este atendimento dentro das escolas públicas e privadas.

Para Paulo Freire, "ensinar exige compreender que a educação é uma forma de intervenção no mundo" (FREIRE,1999, p.11 ). O ato de ensinar é, portanto, político social, científico 
e técnico, refletindo necessidades e expectativas de uma escola para todos.

Refletir um currículo emancipatório e democrático poderá ser o marco principal entre a inclusão de fato e a efetividade das propostas inclusivas. Vale ressaltar também a importância de formação apropriada aos docentes que recebem cotidianamente crianças com deficiências diversas em sala de aula, metodologias, recursos e didáticas especificas, bem como a identidade cultural deve ser respeitada, atendendo ao princípio da flexibilização, haja vista que a Lei de Diretrizes e Bases da educação nacional 9394/96 (LDB) e o Estatuto da Criança e do Adolescente (ECA), afirmam que é incumbência dos docentes zelar pela aprendizagem do aluno com necessidades especiais. "Na escola inclusiva professores e alunos aprendem uma lição que a vida dificilmente ensina: respeitar as diferenças, esse é o primeiro passo para construir uma sociedade mais justa". (MANTOAN, 1997, p. 24-26).

O desenvolvimento de aprendizagens para a autonomia do educando é uma das grandes metas na educação para crianças com deficiência, a produção da linguagem por exemplo, é garantir-lhes o direito de sujeitos históricos, produtores de cultura

A aprendizagem da linguagem é a condição mais importante para o desenvolvimento mental, porque, naturalmente, o conteúdo da experiência histórico-social, não está consolidado somente nas coisas materiais; está generalizado e reflete-se de forma verbal na linguagem. (VYGOTSKY, 1989, p. 114).

Dentro do processo educativo às crianças com deficiência, destaca-se a importância dos pais e familiares na construção de uma escola inclusiva, pois além da produção de uma cultura de valorização às especificidades dessas crianças, há também a 
possibilidade e garantia de um reforço emocional e estrutural na trajetória natural da inclusão.

Vivenciamos em um passado recente uma tendência pedagógica liberal, onde os professores eram os donos das salas de aula, os coordenadores eram os donos dos professores e os gestores eram donos da escola e do material humano, dando ordens, impondo limites, cerceando direitos.

A partir de estudos e pesquisas, estes modelos deixaram de ser suficientes, partindo para uma perspectiva democrática de escola cuja participação da comunidade é instrumento essencial para que a gestão tome as decisões de forma a atender as necessidades da escola, mas também da comunidade em que ela está inserida. Ao pensarmos em educação inclusiva, há que se pensar em políticas públicas entre os órgãos de apoio ao aluno com deficiência.

A escola e a família são contextos do desenvolvimento dos indivíduos com papéis complementares no processo educativo cujo significado cultural, económico e existencial (...) reside no encontro dinâmico das realidades, valores e projetos de cada uma destas unidades sociais" e ainda "a tarefa de educar as gerações mais novas compete, em primeiro lugar, à família e logo em seguida à escola. Ambas são agentes de educação do mesmo sujeito, mas cada uma tem a sua especificidade, quer no conteúdo da educação, quer nos métodos utilizados (TEIXEIRA, 2006, p. 5).

Para que não se sintam ameaçadas, abandonadas, excluídas ou rejeitadas em sala de aula, é importante que os pais participem efetivamente na inclusão de seus filhos, e para tanto, o professor tem um papel importante de orientar e permitir que os pais desses alunos participem ativamente no processo de ensino-aprendizagem dos filhos. Esses pais precisam, nas palavras de Nielsen (1999), ter um canal aberto e sempre acessível à sala, ao professor e à permanência em sala, se for o caso. 
Para que as crianças tenham uma experiência educativa compensadora, os pais têm de ser também envolvidos no processo de inclusão. O professor, antes da colocação da criança na classe regular, deve convocar reuniões com os pais e deve, igualmente, convidá-los a visitar a classe em questão. É de primordial importância abrir portas de comunicação com os pais. (NIELSEN, 1999, p. 25).

A escola inclusiva deve permitir acesso contínuo aos pais e familiares para que esses possam acompanhar e assistir seus filhos, possibilitando a prática qualitativa na educação.

Como espaço de construção de cultura, o projeto político pedagógico deve garantir um currículo emancipatório aos seus educandos, o que implica assistência integral a essas crianças, atendimento especializado e de caráter formativo.

A partir desta perspectiva, a Lei $n^{\circ} 13.146$ foi alterada para incluir o Profissional de Apoio que diariamente tornará cada vez mais possível o atendimento integral das crianças e adolescentes das escolas públicas e privadas, promovendo às famílias, crianças, professores e comunidade, um apoio colaborativo ao trabalho de equidade à pessoa com deficiência.

Dentro desta perspectiva de inclusão para todos, independentemente de sua condição física ou intelectual, cabe à escola, professores, comunidade e pais, promoverem a autonomia para essas crianças. O Profissional de Apoio, embora seja um direito à criança com deficiência, deve estar presente na vida escolar de alunos com extrema necessidade física e ou intelectual, buscando a cada momento incluí-lo de maneira autônoma ao ambiente da escola, entendendo que a verdadeira inclusão acontece quando esta criança ou jovem consegue por meios próprios manter relação de articulação com o meio, interagir com as demais crianças, evoluir dentro de suas maiores possibilidades e potencialidades. 


\section{PECULIARIDADES DO CONCEITO DE DEFICIÊNCIAS E OS SERVIÇOS DE APOIO}

É de suma importância conhecer os diferentes tipos de deficiências, suas peculiaridades, aspectos e espectros, bem como suas principais características, e desta forma, promover a autoestima, potencialidades e possibilidades de inclusão total dentro e fora da escola.

O conceito de inclusão, apesar de estar profundamente vinculado às deficiências das crianças, ampliou-se nos debates e nas políticas públicas educacionais. A concepção de diversidade e singularidade das pessoas mostra que cada bebê e cada criança devem ser vistos como uma pessoa diferente das demais, com interesses e necessidades próprias e que precisa de uma intervenção pedagógica construída a partir das suas características e de seu grupo de colegas. (SÃO PAULO, 2019, p. 33).

No Brasil o documento que trata o direito de inclusão escolar é a Política Nacional de Educação Especial na perspectiva da Educação Inclusiva (2008), como objetivo de "garantir que haja a inclusão escolar de alunos com deficiências, transtornos de desenvolvimento global e altas habilidades para que esses tenham acesso, com participação ativa, no processo de aprendizagem em qualquer nível de ensino regular". (BRASIL, 2008, p. 14). Essa legislação garante a participação de outros profissionais que venham somar aos fatores de inclusão.

Diferentes condições motoras que acometem as pessoas comprometendo a mobilidade, a coordenação motora geral e da fala, em consequência de lesões neurológicas, neuromusculares, ortopédicas, ou más formações congênitas ou adquiridas. (BRASIL, 2008). 
A legislação dá suporte às iniciativas de inclusão e quebra de barreiras para garantir o direito de ir e vir das pessoas com deficiência. A Declaração de Salamanca, no encontro de uma promoção de Educação Inclusiva:

As diferenças humanas são normais e que a aprendizagem deve se adaptar às necessidades das crianças ao invés de se adaptar a criança a assunções preconcebidas a respeito do ritmo e da natureza do processo de aprendizagem. (BRASIL,1994, p. 4).

A grande demanda reside no atendimento das diferentes necessidades, pois suas peculiaridades requerem especificidades, como seguem alguns exemplos entre tantos outros, que são alvos de estudos e pesquisas: ao aluno cego, um material em Braille, e marcações no piso para o seu percurso e mapas táteis para localização; paralisia cerebral necessita de recursos pedagógicos adaptados para a suas limitações e capacidades: ao aluno surdo precisa de um intérprete de Libras, e assim por diante, deixando claro que todas essas especificidades necessitam de estratégias para que a aprendizagem desses alunos aconteçam de fato, e de modo coerente, garantindo o direito e a equidade individua, onde paralelemente, a autonomia também vai ganhando espaço nas vidas destes alunos.

O princípio básico da inclusão escolar consiste em que as escolas reconheçam diversas necessidades dos alunos e a elas respondam, assegurando-lhes uma educação de qualidade, que lhes proporcione aprendizagem por meio de currículo apropriado e promova modificações organizacionais, estratégias de ensino e uso de recursos, dentre outros quesitos. ( MENDES,2002).

Foi aprovada a alteração da Lei no $13.146 / 15$, que dispõem sobre o projeto que trata especialmente sobre o Profissional de 
Apoio Escolar, com formação mínima nível superior (exceto na atuação da educação básica), prestando os cuidados básicos e atividades articuladas ao que acontece dentro da sala de aula. $\mathrm{O}$ Estatuto da pessoa com Deficiência determina no inciso XIII do Art. $3^{\circ}$ que:

Apoio escolar é o apoio em atividades de alimentação, cuidados pessoais e locomoção, bem como na inclusão pedagógica do estudante com deficiência, sob a forma de acompanhamento individualizado e de promoção, em caráter geral, da inclusão na instituição de ensino e na sua proposta político-pedagógico. (referência).

Os Profissionais de Apoio são resultados de lutas e projetos que garantam as condições necessárias e o pleno acesso dos estudantes dentro da escola, pois em conjunto ao profissional docente, participará no processo de inclusão de muitas crianças que anteriormente não frequentavam os espaços escolares devido suas complicações físicas, ou mesmo a grande demanda escolar já existente dentro das salas de aula. Quando falamos em educação inclusiva e nos recursos necessários para que ela aconteça de fato, é fundamental pensar sobre o Profissional de Apoio.

Embora o Profissional de Apoio e o Professor regente sejam dois profissionais essenciais para o processo inclusivo de aprendizado e de desenvolvimento dos alunos com algum nível de deficiência, é importante ressaltar que existem diferenças entre estes. Garantir os conteúdos explícitos por meio da Base Nacional Comum Curricular de Ensino, é papel do professor, mesmo às crianças com deficiência, atribuindo-se ao Profissional de Apoio o compromisso de auxiliar e mediar o processo de ensino da criança com deficiência, adaptado pelo professor da sala se assim houver a necessidade.

Caberá ao Profissional de Apoio, receber as atividades por parte do professor da escola, e assim auxiliar a criança/jovem 
na realização das mesmas, ajudar na locomoção e alimentação, bem como outras questões necessárias ao pleno atendimento das crianças.

Dentre os serviços da educação especial que os sistemas de ensino devem prover estão os profissionais de apoio, tais como aqueles necessários para promoção de acessibilidade e para atendimento a necessidades específicas dos estudantes no âmbito da acessibilidade às comunicações e da atenção aos cuidados pessoais de alimentação, higiene e locomoção (BRASIL, 2010, p. 1).

O professor regente é responsável pela formação e aprendizado de toda uma turma, já o Profissional de Apoio é um agente mediador do desenvolvimento e aprendizado do aluno com deficiência, fruto de lutas e políticas públicas no trajeto da história de pessoas com deficiências, sempre com o entendimento de promover a autonomia progressiva do aluno.

O serviço de poio é um atendimento educacional ao aluno que necessita de auxílio e mediação em tempo integral e irá auxiliar o professor regente e a equipe técnico- pedagógica da escola no trabalho com estes alunos (MOUSINHO. et.al., 2010).

A educação inclusiva parte do pressuposto de que somos todos únicos e que, por isso, o processo de inclusão de cada estudante também é singular. Assim, a necessidade de um Profissional de Apoio deve ser avaliada caso a caso, tendo em vista, de um lado, as características do aluno, e do outro as demandas escolares.

XIII - profissional de apoio escolar: pessoa que exerce atividades de alimentação, higiene e locomoção do estudante com deficiência e atua em todas as atividades escolares nas quais se fizer necessária, em todos os níveis e modalidades de ensino, em instituições públicas e privadas, excluídas as técnicas ou os procedimentos identificados com profissões legalmente estabelecidas. (BRASIL, 2010, p. 1). 
A função deste profissional tem por objetivo promover a autonomia e independência do educando, além dos cuidados e atendimento as necessidades de higiene, alimentação e locomoção dos estudantes que precisem destes cuidados. Este profissional também poderá receber outras nomenclaturas funcional de trabalho, conforme a rede de ensino, localidade ou mesmo política pública específica.

O Profissional de Apoio também atua como mediador nas atividades escolares, e por isso precisa ser orientado e supervisionado quanto às suas ações para realizar e garantir integralmente o planejamento do professor, que, se necessário, fará as devidas adequações nas atividades pedagógicas, a fim de que os educandos participem igualmente das aprendizagens.

Segundo Brandão e Ferreira (2016), a filosofia da inclusão apela para uma escola que tenha atenção à criança - todo, e não só a criança - aluno, respeitando os níveis de desenvolvimento essenciais (acadêmico, sócio emocional e pessoal) de forma a lhe proporcionar uma educação apropriada, orientada para a maximização do seu potencial.

Diante dessas colocações, o papel do Profissional de Apoio na educação inclusiva, contribui com a superação de barreiras, norteando a prática do profissional, e principalmente inclusão social e cidadania.

\section{CONSIDERAÇÕES FINAIS}

A atualidade educacional brasileira vem construindo historicamente suas facetas no âmbito educativo como um todo. Há algumas décadas atrás eram raras cenas onde se podiam ver a participação e permanência de pessoas de todas as idades nos espaços escolares com algum tipo de deficiência. Os cursos de formação profissional para esta área em específico, também eram mais escassos e de pouco interesse, os espaços públicos e privados eram construídos sem a necessidade de projetos adaptados para locomoção de pessoas cadeirantes, cegas, surdas entre outras deficiências. 
As escolas não eram pensadas para receberem tais alunos, pois não compreendiam que essas pessoas poderiam frequentá-las, nem tão pouco conquistarem algum tipo de conhecimento, diante de suas deficiências.

A Lei no 13.146/15 Lei Brasileira de Inclusão da Pessoa com Deficiência (Estatuto da Pessoa com Deficiência), fruto de reconhecimento e luta social de toda uma comunidade com deficiências múltiplas, se destina a assegurar condições de igualdade e equidade às crianças e jovens com deficiência, visando a inclusão social e cidadania de direitos, que já havia sido apontada na Constituição Federal 1988 e consolidada em 1996 por meio da Lei de Diretrizes e Bases, com o objetivo de oferecer e garantir o acesso e permanência de todas as crianças e jovens com deficiência, aos espaços escolares, bem como uma aprendizagem de inclusão e igualdade.

O Profissional de Apoio vem para garantir o direito às crianças com deficiência, a total liberdade de estarem em escolas públicas e privadas diariamente, pois seu papel enquanto Profissional de Apoio, valida a possibilidade dos Profissionais Docentes atuarem com um auxílio legítimo e direto às crianças que assim necessitem, mas que em condições sem apoio, não seria possível, haja vista as especificidades destas crianças e jovens, que muitas vezes, e a depender do grau de comprometimento de sua deficiência, o impediria (professor), de exercer com autonomia seu plano de aula, e até mesmo de não alcançar as necessidades de todas as crianças igualmente.

Todas as escolas no momento de suas formações continuadas e elaborações do projeto político pedagógico, devem prever projetos específicos que incluam de fato todas as crianças e jovens com algum grau de deficiência, cabendo a equipe docente e equipe gestora agirem como facilitadores neste processo dinâmico. O documento Base Nacional Comum Curricular, reconhece que ainda existe um entendimento de educação especial, como uma educação voltada a crianças com deficiência, porém 
valoriza e defende um conceito de que a educação inclusiva é aquela que inclui de forma respeitosa todas as necessidades das crianças e jovens atendidas nos espaços escolares, bem como suas especificidades, desta forma, embora a Lei garanta o Profissional de Apoio às crianças com deficiência, é importante ressaltar um trabalho que desenvolva e garanta a tais crianças especificamente, atitudes de autonomia, pois é esta autonomia que permite que as crianças relacionem-se entre si igualmente.

Quando uma criança com deficiência é estimulada a desenvolver suas potencialidades, muitas vezes consegue atingir um grau de autonomia para a linguagem, marcha segura, higiene de seu próprio corpo, alimentação, entre outras atividades que a aproximam cada vez mais das vivências realizadas com todo o grupo de alunos. Desta forma, não há necessidade deste Profissional de Apoio estar diretamente ligado a esta criança, a mesma conseguirá por si só e dentro de suas possibilidades, interagir e construir seu próprio espaço na convivência com o grupo e professora.

Cada escola possui sua própria forma de desenvolver seus projetos, desta maneira, caberá ao grupo estar em constante avaliação para que se saiba o momento de se permitir o afastamento do Profissional de Apoio de determinada criança, ou mesmo identificar previamente, qual criança realmente necessita da interferência direta deste profissional junto ao professor em sala de aula.

Cada vez mais a inclusão precisa ser pensada e construída de forma significativa, políticas públicas elaboradas nas principais demandas, formações continuas de professores e investimentos que assegurem a inclusão como parte fundamental de nossa sociedade e nos direcionando à cidadania. 


\section{REFERÊNCIAS}

BRANDÃO, M \& FERREIRA, M. Inclusão de crianças com necessidades educativas especiais na educação infantil. Revista Brasileira de Educação Especial. v. 19, n. 4, 2016. Disponível em: . Acesso em: 27 set. 2019.

BRASIL. LEI N9394, DE 20 DE DEZEMBRO DE 1996. Lei de diretrizes e bases educacional.

BRASIL. Ministério da Educação. Política Nacional de Educação Especial na perspectiva da Educação Inclusiva. Brasília: MEC/SEESP, 2008a. Decreto $\mathrm{n}^{\circ}$ 6.571, de 17 de setembro de 2008.

BRASIL, Ministério da Educação. Diretrizes Nacionais para a Educação Especial na Educação Básica / Secretaria de Educação Especial - MEC; SEESP, 2001. Acesso em: 24 maio. 2020.

BRASIL. Constituição . Constituição [da] República Federativa do Brasil. Brasília, DF: Senado Federal, 1988.

BRASIL. Declaração de Salamanca e Linha de Ação sobre Necessidades Educativas Especiais. Brasília: Coordenadoria Nacional para Integração da Pessoa Portadora de Deficiência, Brasília, 1994.

BRASIL. Ministério da Educação. Secretaria de Educação Especial. Nota Técnica $\mathrm{n}^{\circ}$ 19, de 8 de setembro de 2010. Assunto: Profissionais de apoio para alunos com deficiência e transtornos globais do desenvolvimento matriculados em escolas comuns da rede pública de ensino. Brasília: MEC/Seesp/ GAB, 2010. Disponível em: https://inclusaoja.com.br/tag/nota-tecnica/ Acesso em: 25 jun. 2020

CORREIA, L. M. (2008). A Escola Contemporânea e a Inclusão dos Alunos com NEE - Considerações para uma educação com sucesso. Porto: Porto Editora. Acesso em: 24 maio 2020.

COLL, C. Desenvolvimento psicológico e educação - v. 2. Porto Alegre: Artes Médicas Sul, 2014. Acesso em: 13 jul. 2019.

COUTINHO, C. N. Cultura e Sociedade no Brasil. Ensaio sobre Ideias e formas. Ed. Expressão Popular: SP, 2016. Acesso em: 23 out. 2019.

DESSEN, Maria Auxiliadora; POLONIA, Ana da Costa. A família e a escola como contextos de desenvolvimento humano. Ribeirão Preto: Paidéia. v. 17, n. 36. jan./abr., 2007. Disponível em: . Acesso em: 25 set. 2019.

FERREIRA, M. E. C.; GUIMARÃES, M. Educação Inclusiva. Rio de Janeiro: DP\&A, 2013. Acesso em: 25 set. 2019. 
FERNANDES, S. Metodologia da Educação Especial. $1^{\text {a }}$ ed. Curitiba. IBPEX, 2011.Acesso em: 25 set. 2019.

FREIRE, Paulo. Pedagogia da Autonomia. Saberes Necessários à Prática Educativa. São Paulo: Paz e Terra, 1999.

MANTOAN, Maria Tereza Égler; MARQUES, Carlos Alberto. A integração de pessoas com deficiência: contribuições para uma reflexão sobre o tema. São Paulo: Ed. SENAC, 1997.Acesso em: 25 set. 2019.

MENDES, E. G. Perspectivas para construção da escola inclusiva no Brasil. In: PALHARES, M. S.; MARINS, E. S. C. F. (Org.) Escola Inclusiva. São Carlos: EduFSCar, 2002. p. 61-85.

MOUSINHO, R; SCHMID, E; MESQUITA, F; PEREIRA, J; MENDES, L; SHOLL, R \& NÓBREGA, V. Mediação Escolar e inclusão: revisão, dicas e reflexões. Revista de Psicopedagogia, São Paulo, v. 27, n. 82, p. 02-08. Acesso em: 22 nov. 2013.

NIELSEN, L. B. Necessidades Educativas Especiais na Sala de Aula. Um guia para professores. Porto: Porto Editora. 1999.

NIELSEN, L. B. Necessidades Educativas Especiais na Sala de Aula Um Guia para Professores, Colecção Educação Especial, Porto Editora, Lisboa 2010. Acesso em: 25 set. 2019.

SÃO PAULO Secretaria Municipal de Educação. Coordenadoria Pedagógica. Currículo da Cidade: Educação Infantil. São Paulo: SME/COPED, 2019. Acesso em: 24 maio. 2020.

TEIXEIRA, L. Desenvolvimento Pessoal e Social da Criança, na Família e na Escola. Convergência ou Divergência? Covilhã: Universidade da Beira Interior - Departamento de Psicologia e Educação. Acesso em 08 de novembro de 2019.

VYGOTSKY, L. S. A formação social da mente. São Paulo: Ed. Martins Fontes, 1989. BRASIL. Lei 9394 de 24 de dezembro de 1996. Lei Diretrizes e Bases da Educação Nacional. Acesso em: 08 nov. 2019.

UNESCO, Declaração Mundial sobre Educação para Todos. Plano de Ação para Satisfazer as Necessidades Básicas de Aprendizagem. Nova Iorque: WCEFA, 1990. [online] - Disponível em http://www.educacãoonline.pro.br Acesso em: 08 de nov. 2019. 